\title{
Transitando nos limites: uma leitura de As Formigas, de Lygia Fagundes Telles'
}

\author{
Vera Maria Tietzmann Silva
}

ABSTRACT: This article aims to discuss the characteristics of the fantastic present in the short-story "As formigas", by Lygia Fagundes Telles. Emphasis is given to the building up of the atmosphere of hesitation which pervades the text. The theoretical basis for the analysis is provided by Todorov's theory on the subject and some of Poe's critical writings.

KEY-WORDS: Literatura brasileira, conto contemporâneo, ficção fantástica.

\author{
"O fantástico representa uma experiên- \\ cia dos limites". \\ (TzVETAN TODOROV)
}

"Pelo dedo se conhece o gigante", diz o provérbio. Da mesma forma, pela leitura de um conto se conhece a ficção de Lygia Fagundes Telles. "As formigas", publicado pela primeira vez em Seminário dos ratos (1977) e depois republicado em diversas antologias, pode desempenhar esse papel metonímico e dar-nos uma boa idéia da obra da autora. Além de suas evidentes qualidades estéticas, este é um dos "contos do coração" de Lygia, selecionado para o CD da série "O ESCRITOR POR ELE MESMO", do Instituto Moreira Salles, e escolhido por ela própria para abrir a recente coletânea Meus contos preferidos (Rocco, 2004).

Vera Maria Tietzman Silva é professora titular da Faculdade de Letras da Universidade Federal de Goiás. Mestre em Literatura Brasileira pela mesma Universidade.

${ }^{1}$ Palestra proferida na IX Feira Pan-Amazônica do Livro, em Belém do Pará, em 21 de setembro de 2005. 
Muitas características da ficção de Lygia Fagundes Telles podem ser reconhecidas neste texto, ainda que estejam ausentes duas das mais destacadas pela crítica, que são os personagens buscados na burguesia decadente $\mathrm{e}$ o tema dos desencontros amorosos. Quanto à primeira, referente à extração social das duas protagonistas, têm-se informações indiretas, apenas. A narradora descreve a si e à prima como "duas pobres estudantes" que precisam alugar um quartinho de sótão num sobrado decrépito a fim de estudarem na capital - depreendendo-se daí que as duas jovens são interioranas. A declarada pobreza, que poderia ser mera retórica, confirma-se no cardápio barato de seus lanches noturnos: pão, omelete, sardinha, bolachas Maria. A escolha do curso universitário das duas moças revela a preferência que têm por carreiras de prestígio social, Direito e Medicina. Isso tanto pode sugerir que elas sejam burguesas decadentes de famílias tradicionais empobrecidas, como proletárias buscando a ascensão social pelo estudo. De toda maneira, não se trata de Luisianas, Patrícias, Lorenas ou Raízas.

Os desencontros amorosos, que, de tão freqüentes, até nomearam um dos primeiros volumes de contos da autora (Histórias do desencontro, José Olympio, 1954), em "As formigas" só encontram espaço numa caricatura bem-humorada, o sonho obsessivo da narradora, em que ela marca encontro com dois namorados, na mesma hora e local. Na cena descrita neste conto, um dos namorados é o anão.

Embora não se evidencie um conflito amoroso de fato, convém lembrar que, em Lygia, esse tema se inscreve numa dimensão maior, que é a temática dos limites: os limites entre o amor e a indiferença, a sanidade e a loucura, a vida e a morte, temas que comportam, por sua vez, nuanças e variações. Isso nos leva fatalmente à teoria do fantástico de Tzvetan Todorov, em circulação nos meios acadêmicos desde o início dos anos 70, e também à obra de Edgar Allan Poe (1809-1849), o criador do conto moderno, cuja influência pode ser rastreada com facilidade na obra da escritora paulista. ${ }^{2}$

Todorov assinala que "o fantástico representa uma experiência dos limites", ressalvando que tais limites "podem ser de mil tipos" (Todorov, 1992, p.101). Ainda que sua teoria, conforme exposta em sua Introdução à literatura fantástica, não constitua uma unanimidade entre críticos e escritores, ela se ajusta bem à análise tanto dos textos de Poe como dos de Lygia.

Poe, da mesma forma que Lygia, era também fascinado com a questão dos limites, especialmente com as fronteiras que separam a vida e a morte. A morte seria mesmo definitiva? $\mathrm{O}$ desenlace poderia ser sustado? Um re-

${ }^{2} \mathrm{Em}$ outro estudo, já apontamos as semelhanças estruturais das tramas de "O barril de amontillado", de Poe, e "Venha ver o pôr-do-sol", de Lygia (SiLVA, 1992). 
torno seria possível? Essas dúvidas compõem o cerne de muitos de seus contos, como, por exemplo, "O caso do Sr.Valdemar" e "Revelação mesmeriana”, ou "Morela" e "Ligéia”. Nos dois primeiros, o que ele coloca em questão é a tênue fronteira que separa vida e morte; nos outros dois, é o retorno à vida, depois da morte.

Em “As formigas", Lygia Fagundes Telles retoma essas questões ao descrever o misterioso reagrupamento dos ossos de um anão, que o inquilino anterior, estudante de medicina, abandonara numa caixa. Como um filme rodado ao contrário, sob a ação diligente das formigas o esqueleto se recompõe, em processo oposto e igualmente acelerado ao da desintegração do corpo do Sr.Valdemar, no conto de Poe. Consideradas em confronto, essas ações dos dois contos são simétricas. $\mathrm{O}$ movimento para diante ou para trás, de decomposição ou recomposição dos corpos, confere um teor dinâmico à morte, sugerindo sua possível reversibilidade. Em outras palavras, suscitam-se dúvidas sobre aquilo que se convencionou chamar de "a única certeza que temos na vida”.

A premissa fundamental de todo texto fantástico é a ocorrência de um fato insólito. Explicá-lo à luz da racionalidade ou aceitá-lo como manifestação de forças sobrenaturais são as opções que se apresentam ao protagonista. Todorov situa o fantástico na fronteira entre o estranho (que explica o insólito pela razão) e o maravilhoso (que aceita a intervenção do sobrenatural). Por isso diz que o fantástico é um "gênero evanescente", uma vez que "dura apenas o tempo de uma hesitação" (Todorov, 1992, p.47). Para que essa hesitação seja partilhada simultaneamente por protagonista e leitor, possibilitando a instauração do fantástico, é preciso mais do que o fato insólito, é preciso que o escritor construa um clima de instabilidade, de hesitação, que começa no protagonista e se estende até o leitor. E nesse domínio, a lição ainda é de Poe.

Teorizando sobre a construção literária, esse autor lançou as bases do conto moderno ao postular o princípio do "efeito único", que consiste em fazer convergir todos os elementos do texto para a obtenção de um efeito emocional previamente escolhido. E adverte que, se a primeira frase do conto não estiver direcionada para isso, o escritor terá cometido um erro já no seu primeiro passo (POE, 1974, p. 446). Mas como esse efeito, que também poderíamos chamar de atmosfera emocional, é construído com palavras num dado conto?

Lygia é uma exímia criadora de atmosfera e suas narrativas reafirmam os princípios prescritos pelo escritor americano, levando muitas de suas narrativas aos domínios do fantástico, ao somar aos acontecimentos insólitos a hesitação de seus protagonistas em interpretá-los. "As formigas" é um bom exemplo dessa sua mestria, conforme veremos. 
Para criar a atmosfera desejada, a autora lança mão de diversos artifícios, trabalhando seja com os elementos próprios da narrativa (personagens, ação, tempo, espaço, narrador), seja com o modo de construí-la (técnicas de abertura e fechamento, ritmo das ações, etc). Vejamos, a seguir, como Lygia obtém o clima de insegurança e de medo neste conto selecionado.

Em primeiro lugar, levemos em consideração as duas protagonistas, universitárias pobres que alugam um quartinho na casa de uma velha senhora. Uma das moças faz Medicina, a outra Direito. Este parece ser, à primeira vista, um dado aleatório, insignificante mesmo. Mas não - afinal, segundo a teoria de Poe, tudo deve servir ao propósito estabelecido -, pois essa escolha sugere uma oposição, modos opostos de aproximar-se da realidade, que se confirma pelas ações: a aluna de Medicina é dotada de mente lógica, racional, enquanto sua prima é altamente intuitiva e emocional. Esse perfil distinto manifesta-se nas atitudes que tomam. A primeira é disciplinada, estuda até tarde, providencia os mantimentos. Tambémé ela quem se propõe a observar o fenômeno de perto, noite após noite, e é também quem toma as decisões pelas duas. A narradora, ao contrário, é medrosa (recusa-se a olhar os ossos do anão), insegura (tem sonhos obsessivos), infantil (dorme com um urso de pelúcia), tem pouca autodisciplina (na festa a que vai bebe até passar da conta), é imaginativa (aprecia as gravuras de Grassmann, de predominante temática medieval). As duas, então, formam um contraponto, um oscilar de pêndulo entre razão e intuição - vale dizer, entre os pólos do explicável e do sobrenatural, ou entre o estranho e o maravilhoso. Nesse intervalo instaura-se o fantástico.

Quem ler os contos de Poe constata sua preferência por narradores protagonistas, o que, em se tratando de fatos extraordinários, reforça a verossimilhança das ações. A vivência direta, a experiência de primeira mão, estabelece um vínculo tácito entre narrador e leitor, tornando o relato mais acreditável para este. Também a escritora paulista opta pelo narrador de primeira pessoa. Considerando que há duas protagonistas em "As formigas", e que estas, conforme vimos, apresentam perfis psicológicos opostos, é significativo que a narradora seja exatamente a prima insegura, medrosa, infantil, intuitiva. A prima que agasalha o ursinho de pelúcia, como se ele fosse vivo, saído de uma história de fadas. Os estranhos fatos são relatados, então, ao leitor pelo olhar dessa moça, o que contribui grandemente para o clima de dúvida, de hesitação e de medo deste conto.

Ainda com relação aos personagens, há que se considerar outros dois, ocupando papéis secundários, que também se apresentam em oposição. Um deles é real, o outro virtual. São a proprietária da casa, cuja descrição provoca o riso, e o anão em processo de metamorfose, que suscita o medo. 
A dona do sobrado é retratada em traço caricatural, uma descrição que se equilibra, pela via da paródia a Alencar, entre "o grotesco e o sublime":

A dona era uma velha balofa, de peruca mais negra do que a asa da graúna. Vestia um desbotado pijama de seda japonesa e tinha as unhas aduncas recobertas por uma crosta de esmalte vermelhoescuro descascado nas pontas encardidas. Acendeu um charutinho. (TELles, 2004, p.11)

Pouco adiante, menciona-se que ela tem um gato, completando-se a imagem de bruxa, confirmada ao final do conto, quando a prima da narradora insiste em abandonar a casa "antes que a bruxa acorde". Sequer falta a vassoura mágica que, nesta narrativa, parece ter varrido sozinha as formigas mortas:

- E as formigas?

- Até agora, nenhuma.

— Você varreu as mortas?

Ela ficou me olhando.

— Não varri nada. Estava exausta. Não foi você que varreu?

— Eu?! Quando acordei, não tinha nem sinal de formiga nesse chão, estava certa que antes de deitar você juntou tudo... Mas, então, quem?! (Telles, 2004, p.15)

Já o outro personagem, o anão, é temível por sua inconsistência, pela ausência de uma imagem definida. Presença sem corpo como os fantasmas, ele é apenas pressentido pelas estudantes ("senti que no quarto tinha algo mais"). No imaginário da narradora, que lhe dá forma em sonhos, ele assume a figura típica dos anões de circo: "um anão louro de colete xadrez e cabelo repartido no meio entrou no quarto fumando charuto". Note-se como nesta imagem, pela referência ao charuto, superpõemse o anão e a dona do sobrado, compondo um único personagem que congrega oposições diversas: o anão está morto, a mulher, viva; o anão é uma presença virtual, a dona da casa, real; o nanismo justifica-se pelo racional (um acidente genético), a bruxaria explica-se pelo sobrenatural (um ser mágico). Ou seja, juntos, esses dois personagens secundários reforçam os pólos do estranho e do maravilhoso, criando o entrelugar do fantástico. Da mesma forma, as impressões opostas que provocam - o sorriso e o medo - intensificam a hesitação por parte das protagonistas e do leitor. Outra oposição que se percebe entre esses dois personagens são os seus domínios, os lugares onde eles se manifestam, e isso nos leva a considerar o espaço do conto "As formigas". 
Este conto comporta três espaços distintos e interligados: a rua, a casa e o quartinho no sótão. Observando-se a organização das ações nesses três espaços, constata-se que elas se movem de fora para dentro e, depois, em sentido inverso, de dentro para fora. Essa impressão espiralada, ou de círculos concêntricos, fica mais evidente quando é descrito o acesso ao cômodo alugado pelas moças, a "estreita escada de caracol que ia dar no quarto" (TelLes, 2004, p.12). Observemos, então, esses três espaços, considerandoos de dentro para fora.

A escada circular que leva ao sótão, cujo feitio de parafuso sugere o estabelecimento de um centro, é uma imagem dinâmica. Nela ficam implícitos dois movimentos simultâneos, o de subir (ou descer) e o de rodar sobre seu eixo. A escolha desse tipo de escada contribui para o estabelecimento de uma atmosfera de incerteza e para a verossimilhança dos fatos ocorridos no sótão.

Aliás, o acesso ao quarto alugado é feito, de fato, por duas escadas, "a escada velhíssima cheirando a creolina" e "a estreita escada de caracol". As escadas sempre estão presentes nas histórias de Lygia, que tira partido de suas implicações simbólicas. Os degraus da escada, que sempre supõem um movimento, seja ascendente ou descendente, têm o valor simbólico da gradação e da passagem de um nível existencial a outro. A passagem implica ruptura. Subir uma escada é afastar-se do plano da realidade. Subir duas, ainda mais sendo uma em caracol, significa afastar-se duplamente do plano da realidade e ganhar um espaço privilegiado onde coisas extraordinárias podem ocorrer. Assim, o quarto das moças apresenta-se como o cenário ideal para acontecimentos bem distantes da trivialidade do dia-a-dia.

A maior parte das ações concentra-se no exíguo espaço do sótão. Poe, em seu conhecido texto "Filosofia da composição", afirma:

Sempre me pareceu que uma circunscrição fechada do espaço é absolutamente necessária para o efeito do incidente insulado e tem a força de uma moldura para um quadro. Tem indiscutível força moral para conservar concentrada a atenção e, naturalmente, não deve ser confundida com a mera unidade de lugar. (Poe, 1997, p.918)

De fato, os contos de maior impacto desse escritor situam-se em lugares fechados ("O poço e o pêndulo", "Ligéia", "A máscara da morte rubra", "A queda do solar de Usher", etc) e Lygia optou pelo mesmo recurso em "As formigas". Aliás, aqui não se trata de um mero espaço fechado, mas de um sótão que, como o porão, constitui metáfora do subconsciente, um local onde tudo pode acontecer. Este é o domínio do misterioso anão. A dona da casa, por sua vez, move-se nos espaços periféricos do restante da 
casa. São locais de passagem, nos quais a narradora não se detém. Sua menção serve apenas para reforçar a interioridade e o difícil acesso do quartinho no sótão. Quanto ao espaço aberto da rua, que se opõe aos outros dois espaços fechados, ele só comparece na abertura e no fechamento do conto, compondo, via repetição de ações e descrições, a circularidade do conto. Observemos esses dois momentos:

Quando minha prima e eu descemos do táxi já era quase noite. Ficamos imóveis diante do velho sobrado de janelas ovaladas, iguais a dois olhos tristes, um deles vazado por uma pedrada. (Telles, 2004, p.11)

No céu, as últimas estrelas já empalideciam. Quando encarei a casa, só a janela vazada nos via, o outro olho era penumbra. (Telles, 2004, p.18)

Nos trechos transcritos, duas circunstâncias chamam a atenção do leitor: o tempo das ações e a animização do sobrado. Pode-se dizer que "As formigas" é um conto noturno, o que é relevante em termos de construção de atmosfera. Ele começa num início de noite e termina perto de um amanhecer, ou seja, mais ou menos nos horários das marés, nas “horas abertas”, o que lhe dá conotações mágicas. A magia do horário, contudo, é mais nítida na rotina das formigas, que invadem o quarto das moças por volta da meia-noite, outra "hora aberta”, propícia à intervenção do sobrenatural. Reforçando essa impressão, a autora insere outros dois índices que remetem às histórias folclóricas: as formigas aparecem em três noites consecutivas, sempre no mesmo horário, e desaparecem ao amanhecer, como os vampiros e lobisomens.

Voltando às cenas de abertura e fechamento do conto, percebemos que a casa é humanizada, o que é perfeitamente aceitável em termos simbólicos, uma vez que tanto a tradição folclórica como as teorias psicanalíticas reconhecem na casa a representação do corpo ou da alma humana (MAILlANT, 1972, p.156-160). As janelas ovaladas são os seus olhos, fazendo um contraponto por espelhamento com a conhecida frase de Leonardo da Vinci, que diz serem os olhos "as janelas da alma". Contudo, ao confrontarmos as duas passagens (ver as citações acima), deparamo-nos com um paradoxo que, numa primeira leitura, passa despercebido: "só a janela vazada nos via. O outro olho era penumbra”. Qual deles enxergava, afinal? O olho sadio, como o primeiro excerto sugere, ou o olho cego? A indefinição se dá pela voz da narradora, pondo também em xeque a sua percepção dos demais fatos narrados. Hesita a narradora, hesita o leitor e, na indefinição que não se esclarece, prolonga-se o clima do fantástico para além do término do conto. 
A animização da casa, nesses dois trechos transcritos, reitera-se mais sutilmente no mobiliário do quartinho do sótão, onde há duas camas, dois armários, uma mesa e uma cadeira de palhinha pintada de dourado, ou seja, dois pares de elementos e duas unidades, paralelos aos olhos e orelhas, boca e nariz. Considerando que se localizam no sótão, imagem que é lugarcomum para a cabeça, isso não deixa de ser significativo. Não se trata de um simples espaço físico, de um quarto qualquer, mas é uma casa viva, um quarto que pensa, guarda lembranças e toma decisões. Um cenário plausível para a ocorrência de uma metamorfose.

Como fazem também outros teóricos, Todorov destaca a metamorfose como um dos temas recorrentes nas narrativas fantásticas ${ }^{3}$. Em "As formigas", Lygia atualiza esse tema antigo, já tão desgastado no mito e no folclore, acenando com a perspectiva de ressurreição do anão. Dizemos "perspectiva" porque, de fato, nada se esclarece no âmbito do conto. Vejamos.

Há pouco apontamos uma semelhança "pelo avesso" deste conto de Lygia com "O caso do Sr.Valdemar", de Poe. Na experiência que o narrador deste último conto realiza para tentar protelar a morte de um doente terminal pela via do hipnotismo, ele tem o cuidado de cercar-se de testemunhas, o que assegura ao leitor não se tratar de um embuste. Lygia, deliberadamente, conserva uma disfarçada ambigüidade em relação a esse ponto, de tal maneira que o leitor permanece o tempo todo em dúvida sobre os acontecimentos narrados.

Ocorre que o leitor sempre parte do pressuposto de que o narrador é confiável e, pois, acredita no que ele lhe conta. A narradora de "As formigas" relata os fatos acontecidos em sua presença, no lapso temporal de três noites, a curta duração de sua estada nessa casa sinistra. Note-se, porém, que, devido ao medo que sente (ela prefere dizer que é nojo), sempre se recusa a olhar dentro do caixotinho de ossos. Ela acredita na palavra de sua prima, em atitude simétrica à do leitor, que acredita na sua. A prima é bastante racional e deveria ser, em princípio, uma narradora também confiável. Contudo, sabemos que ela estuda até tarde, às vezes, madrugada adentro. Ela não poderia ter sonhado, em meio a seus pontos de anatomia, ou ter visto coisas imaginadas, fruto do estresse a que se submete pelo excesso de esforço intelectual?

A visão nem sempre é confiável, especialmente diante de fatos insólitos, motivo pelo qual Todorov incluiu o olhar, assim como seus substitutivos e acessórios (óculos, lentes, espelhos), entre os temas recorrentes do fan-

${ }^{3} \mathrm{Em}$ A metamorfose nos contos de Lygia Fagundes Telles (v. Referências) fizemos um estudo desse tema em um corpus de mais de 70 contos da autora. 
tástico (ToDOROV, 1992, p.115 ss). A confirmar-se a ilusão/sonho/alucinação da prima, estaríamos diante de uma explicação lógica - diante da manifestação do estranho. Nessa direção, existe ainda outra possibilidade de justificativa racional: a dona da casa não estaria fazendo uma brincadeira de mau gosto com as duas estudantes, valendo-se do longo período diurno que passam fora de casa? O perfil psicológico da prima impede o leitor de aceitar prontamente a primeira hipótese; a falta de maiores elementos no texto afasta-o da segunda. Permanece, portanto, a indecisão.

Uma opção pelo maravilhoso também seria possível e estaria de conformidade com o tema central do conto, que é a metamorfose. Esta, aliás, não se limita ao fenômeno de reagrupamento dos ossos do anão. Ela também se dá nas ações periféricas como um processo compartilhado, envolvendo as formigas e as duas protagonistas:

No chão, a trilha de formigas mortas era agora uma fita escura que encolheu. Uma formiguinha que escapou da matança passou perto do meu pé, já ia esmagá-la quando vi que levava as mãos à cabeça, como uma pessoa desesperada. Deixei-a sumir na fresta do assoalho. (Telles, 2004, p.14-15)

Uma formiguinha desgarrada (a mesma daquela noite?) sacudia a cabeça entre as mãos. (Telles, 2004, p.17)

- Voltaram - ela disse.

Apertei entre as mãos a cabeça dolorida. - Estão aí?

-Ela falava num tom miúdo como se uma formiguinha falasse com sua voz. (Telles, 2004, p.17-18)

Se as jovens se comportam como formigas e estas como gente, o trânsito da ossada do anão de volta à vida entra nesse mesmo leque de possibilidades que se abre pela metamorfose.

Além do mais, há que se considerar a presença da bruxa e de seu gato, invocados no começo e no fim do conto. Afinal, as bruxas são capazes de prodígios, basta lembrar as histórias de Branca de Neve e da Bela Adormecida, que aparentemente morreram por ação de bruxaria e depois voltaram à vida. E quanto ao gato, mencionado duas vezes ("Não deixem a porta aberta senão meu gato foge" e "Foi o gato que miou comprido ou foi um grito?"), a tradição popular garante que ele tem sete - ou mesmo nove fôlegos. Portanto, o retorno à vida, na presença de tais elementos, não seria muito estranhável. Como se vê, no contexto criado pela autora, estreitamse e diluem-se as fronteiras entre morte e vida. 
Na construção deste conto, vimos há pouco que a autora atou as cenas do início e do final, dando circularidade à narrativa. $\mathrm{O}$ círculo, como a escada, é uma imagem dinâmica, que supõe movimento e, nesse particular, articula-se com perfeição à escada em caracol por onde as moças têm acesso a seu quarto alugado. Além disso, o formato circular remete à órbita dos astros, o que confere uma dimensão cósmica à narrativa, deixando implícita uma possibilidade de recomeço. A larga utilização de imagens simbólicas, que é um traço estilístico da autora, revela-se extremamente adequada à construção de uma atmosfera fantástica, uma vez que abre ao leitor múltiplas possibilidades interpretativas, em níveis significativos diversos.

Com relação ao desfecho do conto, evidencia-se outra característica das ficções de Lygia, que são os finais em aberto. Também esse artifício, bastante adotado por autores contemporâneos, tornou-se possível na literatura a partir das teorizações pioneiras de Poe, que, pela primeira vez, levou em consideração a existência de um leitor do outro lado de seu texto. Aliás, foi essa constatação que o moveu a estabelecer os pontos básicos de sua teoria do efeito único, cujo objetivo era manipular a emoção do leitor durante o breve momento da leitura, quando sua alma fica à mercê da vontade do escritor (PoE, 1974, p.445 ss). O conto de Lygia não se fecha, nada fica esclarecido para as duas protagonistas, tampouco para o leitor, sobre os estranhos acontecimentos envolvendo a ossada do anão. Se, por um lado, isso é frustrante para quem lê a história, por outro converte-se num desafio. O leitor permanece em hesitação, prolongando a evanescência do clima fantástico muito tempo depois de fechar o livro. Um poder exercido pelo escritor que ultrapassa o que Poe havia pretendido em 1942, quando expôs suas idéias sobre o efeito único no prefácio ao livro Twice-told tales, de Nathaniel Hawthorne.

Outros aspectos a observar no tocante à construção narrativa de "As formigas" são o tempo e o ritmo das ações. O enredo, contado em primeira pessoa retrospectivamente por uma das protagonistas, organiza as ações seguindo a linha da cronologia. As ações, assim ordenadas, sucedem-se num crescendo, num ritmo de aceleração progressiva, que vai intensificando os temores e dúvidas de personagens e leitores. Não há avanços nem recuos no tempo (flashforwards e flashbacks), que segue sempre adiante, como a marcha dos ponteiros de um relógio. Isso serve, pelo menos, a dois propósitos. Primeiro, aguça a curiosidade do leitor, que fica ansioso em saber o que a noite seguinte irá revelar. A ausência de flashbacks impede o arrefecimento da emoção, a ausência de flashforwards inibe a antecipação dos fatos. O outro efeito dessa escolha é a impressão de inexorabilidade como a rota dos astros no céu -, nada é capaz de deter o processo de metamorfose do anão. Por isso, para escapar a esse sortilégio, a única opção que 
se apresenta às duas moças é fugir.

A essa inexorabilidade, Lygia acrescenta outra, própria das narrativas fantásticas, que é o chamado "pandeterminismo". No conto de Lygia, a dona do sobrado informa às novas moradoras:

O inquilino antes de vocês também estudava medicina, tinha um caixotinho de ossos que esqueceu aqui, estava sempre mexendo neles [...] Eu ia jogar tudo no lixo, mas se você se interessa pode ficar com ele. (Telles, 2004, p.12)

Quando fora isso? Há um semestre, um ano, dois? O texto não esclarece este ponto, apenas sugere que nada de extraordinário estava relacionado ao caixote até então. A chegada das duas moças deflagra o processo de metamorfose do anão, que parecia latente, apenas aguardando um sinal, uma senha para iniciar sua marcha irreversível. Por que nesse momento, e não antes ou depois? A resposta está no aludido pandeterminismo, segundo o qual tudo se corresponde, nada é fortuito. Trata-se

de um determinismo generalizado, de um pandeterminismo: tudo, até o encontro de diversas séries causais (ou "acaso"), deve ter sua causa, no sentido pleno da palavra, mesmo que esta só possa ser de ordem sobrenatural. (Todorov, 1992, p.118-119)

Sob essa ótica, coincidências não existem, o que há é um concerto cósmico regendo o mundo e suas criaturas. Num nível mais abstrato, isso significa que o limite entre a palavra e aquilo que ela nomeia, entre a matéria e o espírito, ou entre o físico e o mental deixa de ser nítido, e a metamorfose é o meio mais perfeito de transgressão desses limites imprecisos. Associando a idéia do pandeterminismo ao tema da metamorfose, o teórico conclui:

Pode-se dizer que o denominador comum dos dois temas, metamorfoses e pandeterminismo é a ruptura (isto é, também a revelação) do limite entre matéria e espírito. Eis-nos de repente autorizados a lançar uma hipótese [...]: a passagem do espírito à matéria tornou-se possível. (Todorov, 1992, p. 122)

Justifica-se, assim, a eclosão do processo de recomposição dos ossos em presença das estudantes. Era a hora delas e era a hora do anão, assim estava escrito em seu destino. Inobstante a força de tal determinismo, a autora reserva uma saída às suas protagonistas, que se recusam a presenciar o momento epifânico do retorno do anão à vida, concedendo-lhes a fuga na 
SILVA, Vera Maria Tietzman

madrugada. A mesma sorte não tem o leitor, que permanece, como a escada que leva ao sótão, parafusando em sua mente sobre o que de fato teria acontecido no quartinho do sótão.

Ao fim destas breves considerações, que não esgotam as leituras possíveis de "As formigas", podemos comprovar o virtuosismo desta ficcionista brasileira, que se move tão à vontade nos meandros do gênero fantástico. Este conto, como anunciamos no início, é apenas um dedo mindinho, uma pequena amostra. Ele pode, contudo, apontar-nos metonimicamente para a real estatura da grande e sedutora obra literária de Lygia Fagundes Telles.

\section{BIBLIOGRAFIA}

MAILLANT, Charles. O código dos sonhos. Trad. Nathanael Caixeiro. Rio de Janeiro: Civilização Brasileira, 1972.

POE, Edgar Allan. Ficção completa, poesias e ensaios. Trad. Oscar Mendes. Rio de Janeiro: Nova Aguilar, 1997.

Selected writings. Middlesex: Penguin, 1974.

TELLES, Lygia Fagundes. Meus contos preferidos. Rio de Janeiro: Rocco, 2004.

. Seminário dos ratos. Rio de Janeiro: José Olympio, 1977.

TODOROV, Tzvetan. Introdução à literatura fantástica. São Paulo: Perspectiva, 1992.

SILVA, Vera Maria Tietzmann. A metamorfose nos contos de Lygia Fagundes Telles. 2. ed. Goiânia: Editora da UFG, 2001. $\overline{1992}$.

A ficção intertextual de Lygia Fagundes Telles. Goiânia: Editora da UFG, 